\title{
The use of visual risk communication and its significance for risk understanding and health literacy in out-clinic settings - a literature review
}

\section{Louise Drejer Jensen}

Research Unit of General Practice, Department of Public Health, University of Southern Denmark

Jesper Bo Nielsen ( $\boldsymbol{D}$ jbnielsen@health.sdu.dk)

Research Unit for General Practice https://orcid.org/0000-0002-5764-5462

Anders Elkær Jensen

Research Unit of General Practic, Department of Public Health, University of Southern Denmark

\section{Research article}

Keywords: Risk understanding, risk communication, visual communication, outpatient clinic, health literacy and general practice

Posted Date: June 14th, 2019

DOI: https://doi.org/10.21203/rs.2.10355/v1

License: (c) (i) This work is licensed under a Creative Commons Attribution 4.0 International License. Read Full License 


\section{Abstract}

Background Patients frequently experience difficulties understanding communicated risks. The aim of this study was through a literature review to analyze if the use of visual risk communication tools improve risk understanding among patients in outpatient settings or general practice, and if one tool appears more useful than others. Method The electronic databases PubMed and PsycINFO were systematically searched. Relevant references were used for chain search to make sure all relevant literature was included. Results The main search revealed 1,157 titles. There were 13 eligible studies concerning visual risk communication in outpatient clinical settings. The design, quality and main findings of the studies were heterogeneous. However, most of the analysed studies found a significant positive effect of graphical, interactive and dynamic visual aids on risk communication. Conclusion There is currently not enough evidence to endorse one graphical format above others. Personalising the graph format to the type of risk information presented may facilitate a better understanding of risk and contribute to improve health and cost-efficacy.

\section{Discussion And Conclusions}

The effect of presenting risk communication visually

Most of the analysed studies $(3,23-27,29-31,33)$ found a significant positive effect of visual risk communication within all fields; static- and interactive graphs, illustration and video. Hawley et al. showed that viewing pictographs was associated with an adequate level of knowledge, especially for individuals with lower numeracy (3). This was supported by McCaffery et al. (31) who found that for adults with low education and low health literacy, pictographs were the best format to use when displaying small numerators $(<100 / 1000)$. For larger numerators $(>100 / 1000)$ bar charts were found to be the optimal choice (31). Comparing the results confirmed that the usefulness of the graphical format depended on the message to be conveyed.

Layout and design are of great importance

The design of the VI is essential to support the patient's understanding. Zikmund-Fisher et al. (32) found that static pictographs with grouped icons in the bottom of the array consistently resulted in a better treatment choice by the patient and improved the ability of the patients to choose the less risky of several treatment options. Results by Fraccaro et al. (22) demonstrated the patients' difficulties in interpreting graphically displayed laboratory tests, as more than $65 \%$ of the patients misjudged the need for action at least once across all scenarios, even though abnormal values were highlighted using colours and graphical cues. These findings emphasize the importance of the graphical design regarding type, colour, cues, complexity, scale and animations in order to inform rather than confuse the patients. Tailoring the graph format to the type of information needed for a particular medical decision would likely produce the most informed patient (3) and thereby hopefully the best decisions. Clear evidence for an association between level of understanding and level of decision-making is still to be investigated.

It is essential that the effects of an intervention can be measured by an outcome. The examination of a colour-coded BP diary showed no significant difference in values of BP, change in AHT or adherence to the diary between the groups after six months (26). Many of the patients (66 \%) had already used home BP measurement before the study, which may have reduced the effect that could be measured by introducing the book. The authors highlight that BP control (< $140 / 90 \mathrm{mmHg}$ ) was achieved more often in the intervention group $(p=0.044)$. These results must be interpreted with 
caution since the study design did not include any guideline or action plan according to the BP values measured at home and the proportion of patients with BP control at baseline had not been measured.

These findings support the importance of the study design, in order to develop a VI that can facilitate a more informed discussion, contribute to shared decision making, and increase health-efficacy. Thus, assisting the patients in the lower sociodemographic groups in making the most beneficial health choices.

Communicating risk through visual tools appears beneficial for the patients' understanding. The optimal type of visual tool for communicating risk depends on the message to be conveyed (gist or verbatim knowledge, the size of the risk etc.), health literacy level, and socioeconomic status of the patient. The results support introducing a personalised approach to risk communication based on graphical/visual risk presentation together with numerical information, like tables, in order to enhance risk understanding.

Other aspects of visual communication

There are many aspects that need to be considered when evaluating the usefulness and benefits of a visual communication tool. It is difficult to measure benefits versus costs such as resources needed for implementation or education, licences etc. vs. benefits such as a more informed patient together with lower health costs if co-morbidity and the need for hospitalisation or other healthcare services is reduced. Peiris et al. (25) found that a screen pop-up for the GP improved the frequency in which the patients' risk factors were screened $(p=0.02)$. It is known that screening may result in overtreatment (34), but the results showed no significant differences in prescription rates for AHT, statins or antiplatelets for those at low risk of CVD (25). Thus, indicating that VI did not generate unnecessary medication prescriptions for people with low risk of CVD. There were significant escalations of new prescriptions or an increased number of medicines prescribed in the high-risk cohort, but not a significantly higher proportion of patients receiving medication as prescribed by guidelines. It would have been relevant to explore if the significant increase in screening of patients was associated with reduced incidence of CVD in patients who had not yet been diagnosed or classified as high risk according to a cost-efficacy perspective.

The graphical presentation was preferred by $57 \%$ of the patients $(p<0.001)(33)$ and the most complex graphics were the least preferred by the participants (32). This correlates with Garcia-Retamero et al. who report that patients find information less useful when provided only numerically, in contrast to the doctors who perceived the information as highly useful, with no statistical difference between the numerical or visual display (27). Consequently, the doctors may not experience the same benefit from the VI as the patients; which is an important observation as decision aids are most often introduced by the health care specialist. When the level of numeracy was statistically controlled for, the type of participant no longer had a significant impact on the understanding. This suggests that the preference for VI's is not related to profession but to numeracy. The examination of an online visual decision aid used in primary care showed no significant extension of consultation time, and the variation of the duration of the consultations was significantly lower in the intervention group. The authors suggest that the VI to some extent could result in a more systematic and reproducible discussion between the patient and the doctor (24). With these findings in mind, it would be reasonable to evaluate if the use of a validated $\mathrm{VI}$ in primary care could result in a more focused dialogue with a 
well-prepared patient, a standardisation of the information given, and a more informed health choice without requiring additional resources from the GP.

The potential of "video" in risk communication

Shukla et al. (30) found that an educational DVD equalled the understanding of a second-grade reading brochure, and at the same time outperformed the understanding obtained by brochures of higher reading levels. Hence, it is relevant to study if the video format has the potential to compensate for impaired reading skills along with reduced numeracy or graph literacy and enhance risk understanding. Valázquez-López et al.'s findings suggest that adding a multimedia tool to conventional nutritional therapy is associated with an improvement in health outcomes (23). The two studies have only used the DVD at the clinic, but the video has the potential to be used as infinite repetition of information at home and a way to involve family members by sharing the information given. If the VI was watched as a preparation to an appointment at the doctor, it may also have the potential to facilitate a more informed discussion as proposed in the paragraph above (4.3). Since the video only has to be recorded once, it does not require resources consecutively. Based on the limited evidence, it appears that video as a supplemental risk communication tool could be a way of improving health as well as health literacy significantly. Future studies should investigate if the video format has potential to enhance risk understanding, if it will be more cost effective and/or whether it has a potential to be used at home for enhanced understanding and involvement of patients as well as relatives.

\section{Perspectives for future research}

This review has revealed a lack of RCT studies in the field of visual risk communication. The majority of studies published has been made in small-scale or with hypothetical scenarios. Studies have shown that tests of hypothetical decisions differ from actual behavioural change (35). Consequently, it would be beneficial to measure outcomes that relate to factual behaviour or biochemical parameters instead of risk understanding. This, to make sure that the VI has an impact on the actual health decisions of the patients and not only affects the more theoretical and not so quantifiable risk understanding. Based on the results in Table 1, it would be beneficial to continue studying if visual risk communication can compensate for low educational level, sociodemographic challenges and lack of numerical or graph literacy in order to improve health and prevent disease.

Strengths and limitations of this study

The strengths of this study include the comprehensive search matrix covering the recent ten years and the thorough examination of papers through citation search, which made it possible to extract the current and updated knowledge in the field of visual risk communication in outpatient clinical settings and general practice.

The main limitations of the study are the lack of RCT studies in the field and the heterogeneous nature of the included study designs and outcomes, which made it difficult to make direct comparisons and conclusions. The review may have been limited by including only studies written in English. In case that the search matrix was not adequate in finding all relevant studies, it is likely that relevant RCT's would have appeared through our citation search. 
Conclusion

The design, quality and main findings of the studies are generally heterogeneous. However, most of the analysed studies found a significant and positive effect of visual risk communication on the understanding of risk. There is currently not enough evidence to highlight one specific visual format above others. Personalising the graph format to the type of risk information presented may facilitate a better risk understanding and contribute to improved health and potentially also cost-efficacy.

The variety of the baseline characteristics in the studies analysed (e.g. educational level, age, comorbidity), diseases, and interventions covered limit an overall and aggregate analysis. Since the results indicate a general trend towards an effect of the visual tools across various parameters, the variation ends up reflecting everyday life in primary care and outpatient settings and as such, indicating a possible effect that should be further explored.

The optimal graphical format for increasing understanding of risk depends on the message to be conveyed. Static pictographs were highly useful for patients with lower numeracy and overall the best format for enhancing risk understanding across patient categories and educational levels.

\section{Practice implications}

There is a need for more research into the field of visual communication of risk to actuel patients in general practice. This review has demonstrated a significant and positive effect of visual risk communication in general. Patients with lower numeracy or education level benefit from graphical risk communication, especially pictographs. Video format shoved potential, as it in one study equalled the understanding of a second-grade reading brochure, and outperformed brochures of higher reading levels. Clinicians should try to implement visual risk communication in their everyday practice and, if available, refer to video material in order to optimise the patients' understanding of risk messages.

\section{Declarations}

Availability of data and materials

This is a literature review, and all data presented are available in the cited papers.

\section{Competing interests}

The authors declare that they have no competing interests

Funding 
No funding received

\section{Authors' contributions}

LDJ was responsible for the literature search. All three authors (LDJ, JBN, AEJ) participated in analyzing the literature and writing the manuscript, and all approved the final submission.

\section{References}

1. Barnes AJ, Hanoch Y, Miron-Shatz T, Ozanne EM. Tailoring risk communication to improve comprehension: Do patient preferences help or hurt? Health psychology : official journal of the Division of Health Psychology, American Psychological Association. 2016;35(9):1007-16.

2. Brust-Renck PG, Royer CE, Reyna VF. Communicating Numerical Risk: Human Factors That Aid Understanding in Health Care. Reviews of Human Factors and Ergonomics. 2013;8(1):235-76.

3. Hawley ST, Zikmund-Fisher B, Ubel P, Jancovic A, Lucas T, Fagerlin A. The impact of the format of graphical presentation on health-related knowledge and treatment choices. Patient education and counseling. 2008;73(3):448-55.

4. Soureti A, Hurling R, Murray P, van Mechelen W, Cobain M. Evaluation of a cardiovascular disease risk assessment tool for the promotion of healthier lifestyles. European journal of cardiovascular prevention and rehabilitation : official journal of the European Society of Cardiology, Working Groups on Epidemiology \& Prevention and Cardiac Rehabilitation and Exercise Physiology. 2010;17(5):519-23.

5. Berkman ND, Sheridan SL, Donahue KE, Halpern DJ, Crotty K. Low health literacy and health outcomes: An updated systematic review. Annals of internal medicine. 2011;155(2):97-107.

6. Harris R, Noble C, Lowers V. Does information form matter when giving tailored risk information to patients in clinical settings? A review of patients' preferences and responses. Patient preference and adherence. 2017;11:389-400.

7. Hess EP, Coylewright M, Frosch DL, Shah ND. Implementation of shared decision making in cardiovascular care: past, present, and future. Circulation Cardiovascular quality and outcomes. 2014;7(5):797-803.

8. Wilson EA, Makoul G, Bojarski EA, Bailey SC, Waite KR, Rapp DN, et al. Comparative analysis of print and multimedia health materials: a review of the literature. Patient education and counseling. 2012;89(1):7-14.

9. Miller DP, Jr., Spangler JG, Case LD, Goff DC, Jr., Singh S, Pignone MP. Effectiveness of a web-based colorectal cancer screening patient decision aid: a randomized controlled trial in a mixed-literacy population. American journal of preventive medicine. 2011;40(6):608-15.

10. Waldron C-A. Cardiovascular risk prediction: how useful are web-based tools and do risk representation formats matter? [Ph.D.]. Ann Arbor: Cardiff University, United Kingdom; 2011.

11. Kher A, Johnson S, Griffith R. Readability Assessment of Online Patient Education Material on Congestive Heart Failure. Advances in preventive medicine. 2017;2017.

12. Wells S, Kerr A, Eadie S, Wiltshire C, Jackson R. 'Your Heart Forecast': a new approach for describing and communicating cardiovascular risk? Heart. 2010;96(9):708-13.

13. Garcia-Retamero R, Cokely ET. Designing Visual Aids That Promote Risk Literacy: A Systematic Review of Health Research and Evidence-Based Design Heuristics. Human factors. 2017;59(4):582-627. 
14. Waldron CA, van der Weijden T, Ludt S, Gallacher J, Elwyn G. What are effective strategies to communicate cardiovascular risk information to patients? A systematic 2011;82(2):169-81.

review. Patient education and counseling.

15. Agoritsas T, Merglen A, Courvoisier DS, Combescure C, Garin N, Perrier A, et al. Sensitivity and predictive value of 15 PubMed search strategies to answer clinical questions rated against full systematic reviews. Journal of medical Internet research. 2012;14(3):e85.

16. Cardiology ESo. SCORE Risk Charts: European Society of Cardiology; 2018 [Available from: https://www.escardio.org/.

17. Lund H, Juhl C, Andreasen J, Møller A. Håndbog i litteratursøgning og kritisk læsning. 1 ed. København: Munksgaard; 2014.

18. Medical Research Library OUH. Søgefiltre: Medical Research Library, Odense University Hospital; 2018 [Available from: http://videncentret.dk/guides/search- filters/.

19. McKibbon KA, Wilczynski NL, Haynes RB, Hedges T. Retrieving randomized controlled trials from medline: a comparison of 38 published search filters. Health ～information and libraries journal. 2009;26(3):187-202.

20. Lee E, Dobbins M, Decorby K, McRae L, Tirilis D, Husson H. An optimal search filter for retrieving systematic reviews and meta-analyses. BMC medical research methodology. 2012;12(51):51.

21. The CONSORT group. CONSORT 2010 checklist of information to include when reporting a randomised trial: The CONSORT group; 2010 [Available from: http://www.consort-

statement.org/media/default/downloads/consort\%202010\%20checklist.pdf.

22. Fraccaro $P$, Vigo M, Balatsoukas $P$, van der Veer $S N$, Hassan L, Williams $R$, et al. Presentation of laboratory test results in patient portals: influence of interface design on risk interpretation and visual search behaviour. BMC medical informatics and decision making. 2018;18(1):11.

23. Velázquez-López L, Munoz-Torres AV, Medina-Bravo P, Vilchis-Gil J, Klupsilonnder-Klupsilonnder M, Escobedo-de la Pena J. Multimedia education program and nutrition therapy improves $\mathrm{HbA1c}$, weight, and lipid profile of patients $\quad$ with type 2 diabetes: a randomized clinical trial. Endocrine. 2017;58(2):236-45.

24. Perestelo-Perez L, Rivero-Santana A, Boronat M, Sanchez-Afonso JA, Perez-Ramos J, Montori VM, et al. Effect of the statin choice encounter decision aid in Spanish patients with type 2 diabetes: A randomized trial. Patient education and counseling. 2016;99(2):295-9.

25. Peiris D, Usherwood T, Panaretto K, Harris M, Hunt J, Redfern J, et al. Effect of a computer-guided, quality improvement program for cardiovascular disease risk management in primary health care: the treatment of cardiovascular risk using electronic decision support cluster-randomized trial. Circulation Cardiovascular quality and outcomes. 2015;8(1):87-95.

26. Chmiel C, Senn O, Rosemann T, Del Prete V, Steurer-Stey C. CoCo trial: Color- coded blood pressure Control, a randomized controlled study. Patient preference and adherence. 2014;8:1383-92.

27. Garcia-Retamero R, Hoffrage U. Visual representation of statistical information improves diagnostic inferences in doctors and their patients. Soc Sci Med. 2013;83:27-33.

28. Ruiz JG, Andrade AD, Garcia-Retamero R, Anam R, Rodriguez R, Sharit J. Communicating global cardiovascular risk: Are icon arrays better than numerical estimates in improving understanding, recall and perception of risk? Patient education and counseling. 2013;93(3):394-402.

29. Nieuwkerk PT, Nierman MC, Vissers MN, Locadia M, Greggers-Peusch P, Knape LP, et al. Intervention to improve adherence to lipid-lowering medication and lipid- levels in patients with an increased cardiovascular risk. The American journal of cardiology. 2012;110(5):666-72.

Page $7 / 20$ 
30. Shukla AN, Daly MK, Legutko P. Informed consent for cataract surgery: patient understanding of verbal, written, and videotaped information. Journal of cataract and refractive surgery. 2012;38(1):80-4.

31. McCaffery KJ, Dixon A, Hayen A, Jansen J, Smith S, Simpson JM. The influence of graphic display format on the interpretations of quantitative risk information among adults with lower education and literacy: a randomized experimental study. Medical Decision Making. 2012;32(4):532-44.

32. Zikmund-Fisher BJ, Witteman HO, Fuhrel-Forbis A, Exe NL, Kahn VC, Dickson M. Animated Graphics for Comparing Two Risks: A Cautionary Tale. Journal of medical Internet research. 2012;14(4).

33. Goodyear-Smith F, Arroll B, Chan L, Jackson R, Wells S, Kenealy T. Patients prefer pictures to numbers to express cardiovascular benefit from treatment. Annals of family medicine. 2008;6(3):213-7.

34. Wallis MG. How do we manage overdiagnosis/overtreatment in breast screening? Clinical Radiology. 2018;73(4):372-80.

35. Hildon Z, Allwood D, Black N. Impact of format and content of visual display of data on comprehension, choice and preference: a systematic review. International Journal for Quality in Health Care. 2012;24(1):55-64.

\section{Tables}




\begin{tabular}{|c|c|c|c|c|c|}
\hline $\begin{array}{l}\text { Author } \\
\text { Year } \\
\text { Country }\end{array}$ & $\begin{array}{l}\text { Study } \\
\text { design }\end{array}$ & $\begin{array}{l}\text { Disease } \\
\text { category and. } \\
\text { setting }\end{array}$ & Intervention and comparison & $\begin{array}{l}\text { Significant } \\
\text { results and } \\
\text { conclusions }\end{array}$ & $\begin{array}{l}\text { Comments and } \\
\text { analysis }\end{array}$ \\
\hline $\begin{array}{l}\text { Fraccaro et } \\
\text { al., 2018, } \\
\text { UK (22). }\end{array}$ & $\begin{array}{l}\text { Controlled } \\
\text { trial with } 20 \\
\text { patients. }\end{array}$ & $\begin{array}{l}\text { Kidney } \\
\text { transplanted } \\
\text { patients } \\
\text { viewing } \\
\text { hypothetic } \\
\text { laboratory test } \\
\text { results } \\
\text { /scenarios at } \\
\text { an online } \\
\text { patient portal. }\end{array}$ & $\begin{array}{l}\text { Participants viewed three different } \\
\text { graphical presentations (of } 28 \text { blood } \\
\text { tests) representing a low, medium } \\
\text { and high-risk clinical scenario. } \\
\text { Outcome: Accuracy of the } \\
\text { participants' interpretation of the } \\
\text { risk, measured by three response } \\
\text { options after each scenario: } \\
\text { Calling doctor immediately, arrange } \\
\text { an appointment within four weeks, } \\
\text { wait for next appointment within } \\
\text { three months. }\end{array}$ & $\begin{array}{l}\text { Findings were } \\
\text { not } \\
\text { significantly } \\
\text { different. The } \\
\text { study } \\
\text { confirmed that } \\
\text { the participants } \\
\text { had difficulties } \\
\text { when } \\
\text { interpreting } \\
\text { laboratory test } \\
\text { results. Many } \\
\text { participants } \\
\text { (65\%) } \\
\text { underestimated } \\
\text { the need for } \\
\text { action at least } \\
\text { once even } \\
\text { when abnormal } \\
\text { values were } \\
\text { highlighted } \\
\text { using colours } \\
\text { and graphical } \\
\text { cues. }\end{array}$ & $\begin{array}{l}\text { Applicability } \\
\text { This study } \\
\text { explored whether } \\
\text { a visual } \\
\text { presentation using } \\
\text { colours and } \\
\text { graphical cues can } \\
\text { improve the } \\
\text { patients' ability to } \\
\text { interpret the risk } \\
\text { information } \\
\text { presented. } \\
\text { - } \\
\text { Limitations: } \\
\text { Small cohort, } \\
\text { limited statistical } \\
\text { power. } \\
\text { No evaluation of } \\
\text { graph literacy or } \\
\text { numeracy at } \\
\text { baseline. } \\
\text { The participants } \\
\text { were all used to } \\
\text { being monitored by } \\
\text { biochemical tests } \\
\text { and not } \\
\text { comparable to the } \\
\text { average population } \\
\text { in general } \\
\text { practice. }\end{array}$ \\
\hline $\begin{array}{l}\text { Valázquez- } \\
\text { López et al., } \\
2017, \\
\text { Mexico } \\
\text { (23). }\end{array}$ & $\begin{array}{l}\text { Randomised } \\
\text { clinical trial } \\
\text { with four } \\
\text { primary care } \\
\text { clinics and } \\
351 \text { patients. }\end{array}$ & $\begin{array}{l}\text { Patients with } \\
\text { type } 2 \text { diabetes } \\
\text { (DM-2), } \\
\text { without severe } \\
\text { complications, } \\
\text { in primary } \\
\text { care. }\end{array}$ & $\begin{array}{l}\text { Multimedia education program } \\
\text { (MEP) and nutritional therapy (NT) } \\
\text { compared to a control group who } \\
\text { received NT only. } \\
\text { The NT was personalised according } \\
\text { to comorbidities and nutritional } \\
\text { preferences. } \\
\text { The NT + MEP group was educated } \\
\text { through a MEP named Nutriluv }{ }^{\circledR} \text {. A } \\
\text { specific MEP module was shown in } \\
\text { an informational kiosk prior to the } \\
\text { nutritional session. Duration of } \\
\text { intervention was } 21 \text { months. }\end{array}$ & $\begin{array}{l}\text { Diabetes } \\
\text { education with } \\
\text { MEP was an } \\
\text { effective } \\
\text { strategy to } \\
\text { improve the } \\
\text { HbA1c } \\
\text { (glycated } \\
\text { haemoglobin), } \\
\text { lipid profiles, } \\
\text { and body } \\
\text { weight in the } \\
\text { patients with } \\
\text { DM-2 in the } \\
\text { long term. }\end{array}$ & $\begin{array}{l}\text { Applicability. } \\
\text { DM-2 is a common } \\
\text { disease treated in } \\
\text { primary care with } \\
\text { potentially severe } \\
\text { complication. } \\
\\
\text { Limitations: } \\
\text { No statistical } \\
\text { power calculation, } \\
\text { weak statistical } \\
\text { analysis e.g. } \\
\text { conversion of units } \\
\text { to percent, } \\
\text { adjustments at } \\
\text { baseline even } \\
\text { though the groups } \\
\text { were randomised. } \\
\text { No stratification of } \\
\text { baseline } \\
\text { characteristics. }\end{array}$ \\
\hline
\end{tabular}


Anthropometry measurements were not blinded.

The completion rates of patients were low $(59.5 \%$ and 56.5\%).

\begin{tabular}{lll}
\hline Perestelo- & Cluster & Cardiovascular \\
Pérez et al., & randomised & disease (CVD) \\
2016, Spain & trial with 29 & prevention in \\
(24). & doctors and & patients with \\
& 168 & DM-2 in \\
& patients. & primary care.
\end{tabular}

"Statin choice", is an online clinical
decision tool used in consultations in
primary care. The decision aid
calculates the risk of CVD in the next
ten years, based on personal health
information. The risk is displayed
graphically with 100 dots coloured in
green, red or yellow.

Evaluation of knowledge about statins, perception of CVD risk, decisional conflicts and satisfaction were assessed by questionnaires, immediately after the intervention and at follow up after three months.

Comparison: Usual care.

$\begin{array}{lll}\text { Peiris et al., } & \text { Randomised } & \text { Cardiovascular } \\ \text { 2015, } & \text { controlled } & \text { disease (CVD) } \\ \text { Australia } & \text { trail (RCT) } & \text { risk } \\ \text { (25). } & \text { with } 60 & \text { management } \\ & \text { primary } & \text { in primary } \\ & \text { healthcare } & \text { healthcare. } \\ & \text { centres and } & \\ & 38725 & \\ & \text { patients. } & \end{array}$

\section{The} intervention in primary care. The intervention included a series of traffic light cues, to alert the general practitioner if the patient was not receiving sufficient screening or management. The intervention, for a minimum of 12 months, also included a graphical risk communication tool to assist the patient in understanding their CVD risk and

Intervention
improved
knowledge ( $p$
$=0.01$ ),
perception of
the 10-year risk
of myocardial
infarction
without using
statins ( $p=$
0.01 ) and
satisfaction ( $p$
$=0.01)$.

The communication tool did not increase the length of consultations when compared with usual care.

The variance of consultation time was lower in the intervention group ( $p=$ 0.025), which suggests that the use of the decision tool may result in a more systematic and reproducible discussion. The decision tool improved the quality of the decision making about the use of statins.

Applicability.

This decision tool and its outcome is relevant to risk communication in primary care.

Limitations:

No calculation of sample power.

Unbalanced randomisation regarding age, hypertension and number of patients taking statins at baseline.

Survey instruments were not checked for validity and reliability after the translation into Spanish.

Adherence after three months was self-reported and therefore may have been less reliable.

Doctors and patients were not blinded.

intervention was associated with improved measurements of the patients' risk factors (62.8\% vs. $53.4 \%$, risk ratio 1.25 (95\%

Appplicability

The pragmatic implementation of the tool was relevant to primary care. The outcome was clinical and a low level of implementation 
how the risk could be affected by changes of individual risk factors.

Comparison: Usual care without the intervention tool or training of the general practitioner. Main outcomes were the fraction of patients receiving appropriate screening of risk factors and the proportion of patients receiving the recommended treatment according to guidelines.
CI, 1.04-1.50)

and $p=0.02)$.

support was required.

No significant differences in the proportions receiving

guideline recommended medication prescriptions for the highrisk cohort ( $p$ $=0.12$ ). There were significant treatment escalations for the high-risk cohort (new prescriptions or increased numbers of medicines). There was a higher proportion reaching guideline BP targets in the intervention group versus the control group. The intervention improved the CVD risk measurements and required minimal support.
Chmiel et RCT with 30 Patients with al., 2014, Switzerland (26). general hypertension practices and 137 patients.
(BP > 140 mmHg systolic and/or > 90 $\mathrm{mmHg}$ diastolic), treated in
Daily home BP measurement (HBPM) noted in either a schematic standard non-coloured BP booklet (control group) or a colour-coded booklet (intervention). The scheme in the coloured book was divided into three zones, according to the BP value: green, yellow and red. The duration of the study was six months. Clinical parameters and
Findings showed no significant difference between the groups in absolute BP reduction or adherence with HBPM. The
Strengths:

Large sample size, power calculation has been made.

Adequate representativeness of the clinics included.

Sufficient randomisation with stratification.

Clinical outcome measures.

Outcome analysis were conducted blinded to randomisation.

Inclusion criteria were based on national guidelines for vascular screening.

Limitations:

The doctors received training as a part of the intervention.

Blinding of participants was not possible.

It was not possible to distinguish between the intervention's effect on the patients and the practitioners risk understanding according to the study design.

Applicability.

Simple, low cost and user friendly intervention with low necessity to understand numeracy. Study sample representing adult 
general practice. medication changes were recorded at 0,3 and 6 months.

The outcome measurements: Adherence to HBPM measurements, $B P$ values at follow up at the general practitioner and prescription of antihypertensive medication. target BP

$(<140 / 90$

$\mathrm{mmHg}$ ) was

achieved more

often in the

intervention

group (43\% vs.

$25 \% ; p=$

$0.044)$. No

significant

differences in

adherence with

HBPM,

decrease in

systolic and

diastolic BP at

end-point or

change in Anti-

hypertensive

therapy

(changed in 63

$\%)$ primary care

patients with

hypertension.

Calculation of statistical power and intention to treat analysis.

Computer randomisation at patient level.

Randomisation was adequate.

Precise and detailed manual for the HBPM in order to standardise outcome.

$-$

Limitations:

BP can be affected by medicine, exercise, stress, diet, lifestyle etc. The study design did not include guidelines or action plans according to the $\mathrm{BP}$ values.

Therefore, the patients did not have a standardised way to respond if the BP was above normal value. Their response depended on their own beliefs and health literacy.

The majority of the patients $(\approx 66 \%)$ had already done HBPM before inclusion in the study.

The doctors and the patients were not blinded. Doctor and patient interaction was not investigated.

Possible Hawthorne effect. The calculated sample size was not attained, 
possible type 2

error.

\begin{tabular}{|c|c|c|c|c|c|}
\hline $\begin{array}{l}\text { Garcia- } \\
\text { Retamero } \\
\text { et al., 2013, }\end{array}$ & \multirow{4}{*}{$\begin{array}{l}\text { Randomised } \\
\text { trial with } 81 \\
\text { general } \\
\text { practitioners } \\
\text { and } 81 \\
\text { patients } \\
\text { from four } \\
\text { hospitals. }\end{array}$} & \multirow{4}{*}{$\begin{array}{l}\text { Questions } \\
\text { regarding } \\
\text { diagnostic } \\
\text { inferences of } \\
\text { cancer and } \\
\text { diabetes. }\end{array}$} & \multicolumn{3}{|c|}{$\begin{array}{l}\text { Recruitment during an ordinary } \\
\text { consultation and subsequent } \\
\text { randomisation into four groups (as } \\
\text { shown below). }\end{array}$} \\
\hline \multirow{3}{*}{$\begin{array}{l}\text { Retamero } \\
\text { et al., 2013, } \\
\text { Spain (27). }\end{array}$} & & & $\begin{array}{l}\text { Risk } \\
\text { information } \\
\text { given as: }\end{array}$ & $\begin{array}{l}\text { Natural } \\
\text { frequen- } \\
\text { cies }\end{array}$ & $\begin{array}{l}\text { Probabili- } \\
\text { ties }\end{array}$ \\
\hline & & & Numerical & $\mathrm{A}$ & B \\
\hline & & & $\begin{array}{l}\text { Numerical } \\
+ \text { visual } \\
\text { tool }\end{array}$ & $\mathrm{C}$ & $\mathrm{D}$ \\
\hline
\end{tabular}

In addition, participants completed a numeracy test with 12 items. After receiving information about the prevalence of the disease, and the sensitivity and false-positive rate of the test for a given task, participants made the diagnostic inference about three medical tests.

The outcome measurements: Improvement in diagnostic inferences measured in probabilities or percentages of people having the disease.

Accuracy, perceived usefulness and perceived difficulty with the data representation were also assessed.

Performance was better

when the

information

was presented

in natural

frequencies

and presented

both

numerically

and visually, as

compared to

probabilities

and only

numerical.

Visual tools

improved the

accuracy of

diagnostic

inference for

medical

doctors and

their patients

regardless of the numerical

format.

Numerica format, visual aid, type of participant, level of numeracy as a covariate, and estimates of task difficulty as the only dependent variable, showed a main effect of the

visual aid ( $p=$ 0.016)

The patients estimated information as less useful when it was provided only numerically, as compared to the same information provided both numerically and visually ( $p$ $=0.023$ ).

Overall, doctors had higher numerical skills than their
Applicability

Comparison of numeracy for both the patients and doctors and their inferences.

Randomisation with stratification.

\section{Limitations:}

Small sample size. Statistical section was not adequate and difficult to interpret.

The data analysis was limited by the method used according to data type.

Baseline characteristics:

The patients were older and less educated than the general population.

Outcome was based on inference and perception, not actual behaviour. 
patients

$(p=0.001)$.

$\begin{array}{lll}\text { Ruiz et al., } & \text { RCT at an } & \text { CVD among } \\ \text { 2013, USA } & \text { outpatient } & \text { patients with } \\ \text { (28). } & \text { clinic with } & \text { intermediate } \\ & 120 \text { male } & \text { or high } \\ & \text { participants } & \text { cardiovascular } \\ & & \text { risk. }\end{array}$
computer-based tutorial, which contains a sequential presentation of information regarding risk factors

for coronary disease, their calculated absolute 10-year CVD (Framingham) and a presentation of individualised risks. The risk of a CVD is presented in three formats:

Each participant was compensated with 30 dollars. and knowledge by questionnaire
Your Cardiovascular Risk Score is a
Icon arrays

may impair

short-term

recall of cardiovascular risk. Accuracy

was inferior

with

frequencies + icon arrays compared to percentages or frequencies at T2 $(p=0.001)$ Patients with high graphical literacy performed better than graphical literacy at all times. those with low

Applicability

The patients were at high risk of CVD, which may had a positive influence on their motivation for the risk communication assessment, as they may had to make a life changing decision. immediately (T1), after 20
(T2) and 2 weeks after the intervention (T3). T1 and T2 assessed perception of importance/seriousness, intent to adhere, and self-efficacy. T3 also concerned self-reported adherence.

The numeracy and graph literacy were also assessed.
Statistical analyses explored possible effects of confounding covariates.

The person analysing the data was blinded.

Completion rate by the patients was high (88\%).

\section{Limitations:}

Small sample size and from one clinic.

\section{No sample size/power calculation.}

Participants had baseline differences.

Due to risk perception being self-reported there was no measurement of actual adherence, life-style changes or medical treatments.

\section{Short follow up} period.

The use of two icon arrays: one for actual risk and one for ideal risk may have caused increased cognitive load and 
thereby reduced encoding.

The patients were paid to participate in the study which may change the incitement to attend.

$\begin{array}{lll}\text { Nieuwkerk } & \text { RCT with } & \text { Patients with } \\ \text { et al., 2012, } & \text { two } & \text { indication for } \\ \text { The } & \text { outpatient } & \text { statin therapy } \\ \text { Netherlands } & \text { clinics and } & \text { for primary or } \\ \text { (29). } & \text { 201 patients. } & \begin{array}{l}\text { secondary } \\ \text { prevention of } \\ \text { CVD. }\end{array} \\ & & \end{array}$

Extended care (EC) with nurse-led visual cardiovascular risk factor counselling compared to routine care (RC) at baseline and after 3, 9 and 18 months.

Patients in the EC group received multifactorial risk-factor counselling, and a personalised risk-factor book.

The book showed modifiable and unmodifiable individual risk factors, a graphical presentation of the calculated absolute 10-year CVD risk (Framingham). It was also showing the target risk that could be reached if all modifiable risk factors were optimally treated and the most recent ultrasound image of the patient's carotid artery

Outcome measurements: Statin adherence, quality of life, symptoms, smoking status, blood lipids and the thickness of the carotid intima.
Statin

adherence was

higher $(p<$

0.01 ) and

anxiety was

lower ( $p<$

0.01) in the EC

group. LDL

was lower in

the EC group

compared to

the RC group

$(p=0.024)$.

Intima

thickness

decreased from

baseline in

both groups ( $p$

$<0.01$ ).

Multifactorial

cardiovascular

risk-factor

counselling

resulted in

higher levels of

adherence to

lipid-lowering

medication and

lower LDL

cholesterol

concentrations

in primary

prevention

patients,

without

increasing the

patients'

anxiety

compared to

RC.
Applicability

Randomisation by computer to obtain equal baseline characteristics.

Intention to treat analysis.

Power calculation of sample size.

Higher levels of self-reported adherence to lipidlowering medication was significant and correlated with lower concurrent LDL cholesterol ( $p$ $=0.001$ ), thereby supporting the validity of selfreported adherence.

-

\section{Limitations}

There was a difference in baseline risk perception score between the groups.

All participants had equal amounts of visits with the study nurse practitioner, but the extra time in the EC group was on average 30 minutes per visit. The positive results might have been affected by the prolonged interpersonal contact instead of being a result solely based on the risk-factor book. 
Shukla et al., 2012, USA (30).
Randomised prospective study with 100 patients.
Cataract patients at the department of ophthalmology.
Patients were randomised into one of four groups: 1) Conventional verbal information; 2) conventional verbal information plus secondgrade reading level brochure; 3 ) conventional verbal information plus eighth-grade reading level brochure; 4) conventional verbal information plus an educational DVD made for understanding cataract surgery.

All patients completed a multiplechoice questionnaire (MCQ) with 12 questions and four possible answers for each.

The MCQ revealed understanding of

surgical procedure, its benefits, its

foreseeable and unforeseeable risks, and the alternatives to cataract surgery.

Patients in group 2 and 4 scored higher in

understanding than patients in group 1 or 3 ( $p$ $<0.001)$. The highest education level had no effect on scores $(p>$ $0.05)$. Thus, concise informed information sheets at lower reading grade levels and videotape presentation optimised the understanding of the risks, benefits, and treatment alternatives to cataract surgery.

McCaffery

et al., 2012, Australia (31).

A
randomised
experimental
study with
120
participants.

participants

\section{Adults}

attending government sponsored basic adult literacy and numeracy classes. They volunteered to participate in the study.
The target was to test optimal graphic risk communication formats when presenting small probabilities using graphics with a denominator of 1000. The experimental computerbased manipulation compared three types of graphics; bar charts and pictographs with blocks or dots across horizontal or vertical orientation. The numerator size was divided into three groups: small < 100, medium 100-499 and large 500-999. Participants were asked two questions concerning the treatment of the medical condition

" $\mathrm{X}$ ". One focussing on gist knowledge and one on verbatim knowledge.

Three trainings were completed to ensure that the participants understood the tasks, and how to record their responses before the trial.
For small

numerators, pictographs resulted in fewer errors than bar charts.

For medium and large numerators bar charts were more accurate.

Accuracy on the gist task was very high across all conditions (> $95 \%)$. Vertical formats were processed slightly faster than horizontal graphs with no difference in accuracy. Most participants preferred bar charts (64 \%); however, there was no relationship with performance.
Applicability

Information by video is a reproducible and low cost procedure with potential for implementation in the primary sector.

The education level of the patients was assessed.

\section{Limitations}

No power calculation of sample size.

Uneven baseline characteristics of groups e.g. gender and education level. The MCQ was not validated. Applicability

Socioeconomic deprivation among the participants can be seen as a limitation as they do not represent the population or as a strength because they represent a group that is in most need for better understanding in health-related issues.

The outcome shown as probabilities is a common way of communicating risk and is relevant to the primary care sector.

Limitations:

No direct measure of the participants' literacy or numeracy levels (average age for leaving school was 16.7 years). 
Computer setting, without real patient-physician contact.

No information about the participants' medical history.

\begin{tabular}{|c|c|c|c|}
\hline $\begin{array}{l}\text { Zikmund- } \\
\text { Fisher et } \\
\text { al., 2012, } \\
\text { USA (32). }\end{array}$ & $\begin{array}{l}\text { Randomised } \\
\text { study with a } \\
\text { quasi- } \\
\text { factorial } \\
\text { design and } \\
4198 \\
\text { participants } \\
\text { from a } \\
\text { survey panel } \\
\text { of internet } \\
\text { users. }\end{array}$ & $\begin{array}{l}\text { A fictive } \\
\text { scenario about } \\
\text { two } \\
\text { hypothetical } \\
\text { treatments for } \\
\text { thyroid cancer. } \\
\text { Tested by } \\
\text { internet users } \\
\text { without the } \\
\text { disease. }\end{array}$ & $\begin{array}{l}\text { The study evaluated eight different } \\
\text { animated risk graphics presented by } \\
\text { icons arrays (blocs). They were } \\
\text { viewed on a PC screen that } \\
\text { incorporated different combinations } \\
\text { of three basic animations: 1) } \\
\text { building risk one unit at a time, 2) } \\
\text { settling scattered risk into a } \\
\text { grouping and 3) shuffling scattered } \\
\text { risk to reinforce randomness. } \\
\text { Participants received all risk } \\
\text { information in } 1 \text { out of } 10 \text { possible } \\
\text { pictograph formats. }\end{array}$ \\
\hline
\end{tabular}

Outcome: To test if animated icon array pictographs, displaying risks of side effects, could improve participants' ability to select the treatment with the lowest risk profile, as compared with seeing static images of the same risks.

Outcome measurements: The ability of the participants to choose the less risky treatment (choice accuracy), gist knowledge of side effects (knowledge accuracy), and graph evaluation ratings, controlled for subjective numeracy, and need for cognition.

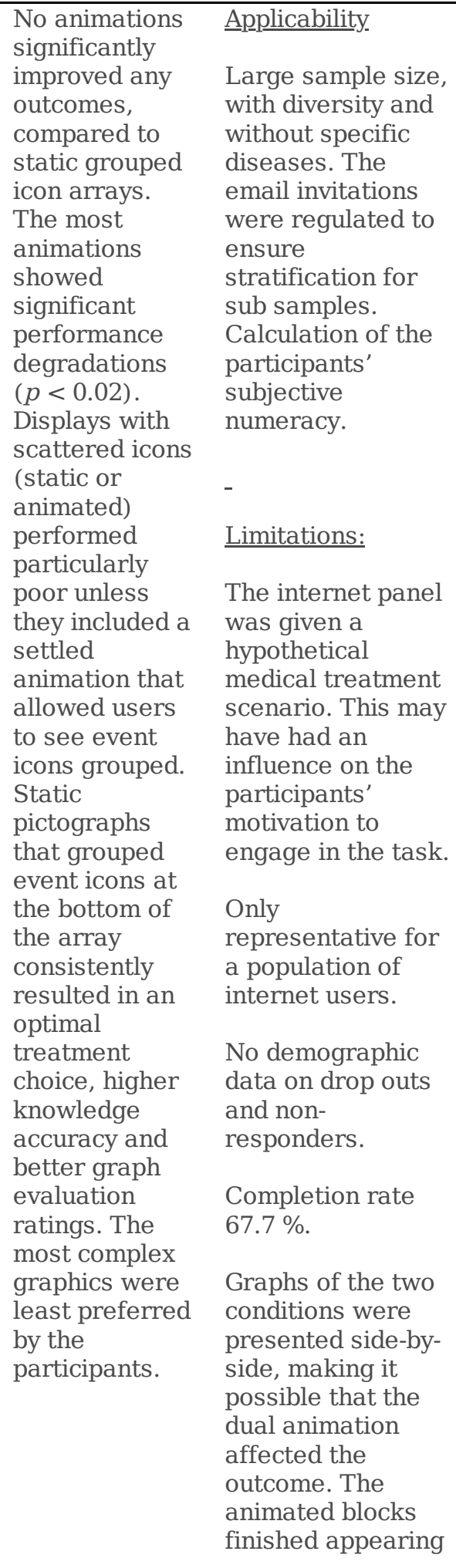




\begin{tabular}{|lll}
\hline Hawley et & Randomised & An online \\
al., 2008, & trial with & hypothetical \\
USA (3). & 2412 & medical \\
& participants & decision- \\
& drawn from & making \\
& a survey & scenario about \\
panel of & CVD. \\
& internet & \\
& users. & Setting: \\
& & General \\
& & practice.
\end{tabular}

\begin{abstract}
Imaginary scenario in general
practice with a choice between two different types of medication to avoid a bypass surgery. One treatment was designed as superior according to its risk profile and beneficial effects. Numerical risk information was given in one out of the following six graph formats; bar graph, pictograph, modified pictograph (sparkplug), pie chart, modified pie graph (clock graph) or in a table.

The aim was to evaluate what impact these six graphical formats had on answers about treatment risks and benefits.
\end{abstract}

The outcome measurements: Verbatim knowledge (the ability to correctly read numbers from graphs) and gist knowledge (the ability to identify the essential points of the information presented). in one of the two arrays before the other one, creating a longer motion cue, which may have affected treatment choice. Applicability.

All formats were positively received, and pictographs were trusted by respondents with both high and low numeracy. High Verbatim and gist knowledge where associated with making a medically superior treatment choice $(p<$ 0.01).

Viewing a pictograph was associated with both adequate verbatim and gist knowledge, especially for individuals with lower numeracy.

Respondents with higher numeracy answered more of the questions correctly for both verbatim and gist knowledge regardless of graph type ( $p<$ 0.007), compared to respondents with low numeracy, none of the graph types were associated with making a correct treatment choice.

Pictographs were the best format for
Email invitations were adjusted to ensure stratification for sub samples. Large sample size.

Numerical understanding was translated into the understanding of consequence.

\section{Limitations:}

Participants were not personally affected by the risk presented, this may have affected the way

risk was interpreted.

Data was only representative for people able to use the internet.

Dropout (23.5 \%), may be due to participants who did not understand the graphs. This has not been explored further.

No real patientphysician contact regarding delivery of medical information.

Numeracy was a validated method, however the questions used for gist and verbatim knowledge were not confirmed validated. evaluated by using 
communicating

probabilistic

information,

particularly

among

individuals with

lower

numeracy.

\begin{tabular}{|c|c|c|c|}
\hline $\begin{array}{l}\text { Goodyear- } \\
\text { Smith et al., } \\
\text { 2008, New } \\
\text { Zealand } \\
\text { (33). }\end{array}$ & $\begin{array}{l}\text { Question- } \\
\text { naire and } \\
\text { telephone } \\
\text { interviews } \\
\text { with } 188 \\
\text { patients } \\
\text { invited } \\
\text { through } \\
\text { four family } \\
\text { practices. }\end{array}$ & $\begin{array}{l}\text { Patients with a } \\
\text { pre-existing } \\
\text { heart disease } \\
\text { and users of } \\
\text { statin. }\end{array}$ & $\begin{array}{l}\text { Patients were interviewed about } \\
\text { their preference for methods } \\
\text { expressing the preventive benefit of } \\
\text { a hypothetical medication. Benefits } \\
\text { were expressed in numerical } \\
\text { formats (relative risk, absolute risk, } \\
\text { number needed to treat, odds ratio } \\
\text { and natural frequency) and one } \\
\text { graphical (bar chart). } \\
\text { The outcome measurements: Could } \\
\text { information presented in a different } \\
\text { way encourage the patient to take } \\
\text { the medication daily, which method } \\
\text { was preferred to express the benefit } \\
\text { of the medication and if the patient } \\
\text { preferred positively or negatively } \\
\text { framed information. }\end{array}$ \\
\hline
\end{tabular}

No matter how Applicability.

the risk was

expressed,

most of the

patients (67-89

$\%)$ indicated

that they would

be encouraged

to take the

medication. A

large group of

the patients

(68\%)

preferred one

method of

expressing

benefits over

the others, but

$32 \%$ of the

patients could

not decide

which

presentation

they preferred.

More than half

(57\%)

preferred the

information

presented

graphically ( $p$

$<0.001)$. The

second most

preferred

option (19\%)

was relative

risk. Most

patients (90\%)

preferred

positive

framing

(description of

the benefits of

treatment)

above negative

framing

(description of

the harm of not

being

treated).A

graphical

representation

of the benefits

was the

method

patients

preferred the

most. 
Table 1. Design characteristics, main findings and comments on the 13 included studies. The studies are listed by year of publication.

\section{Figures}

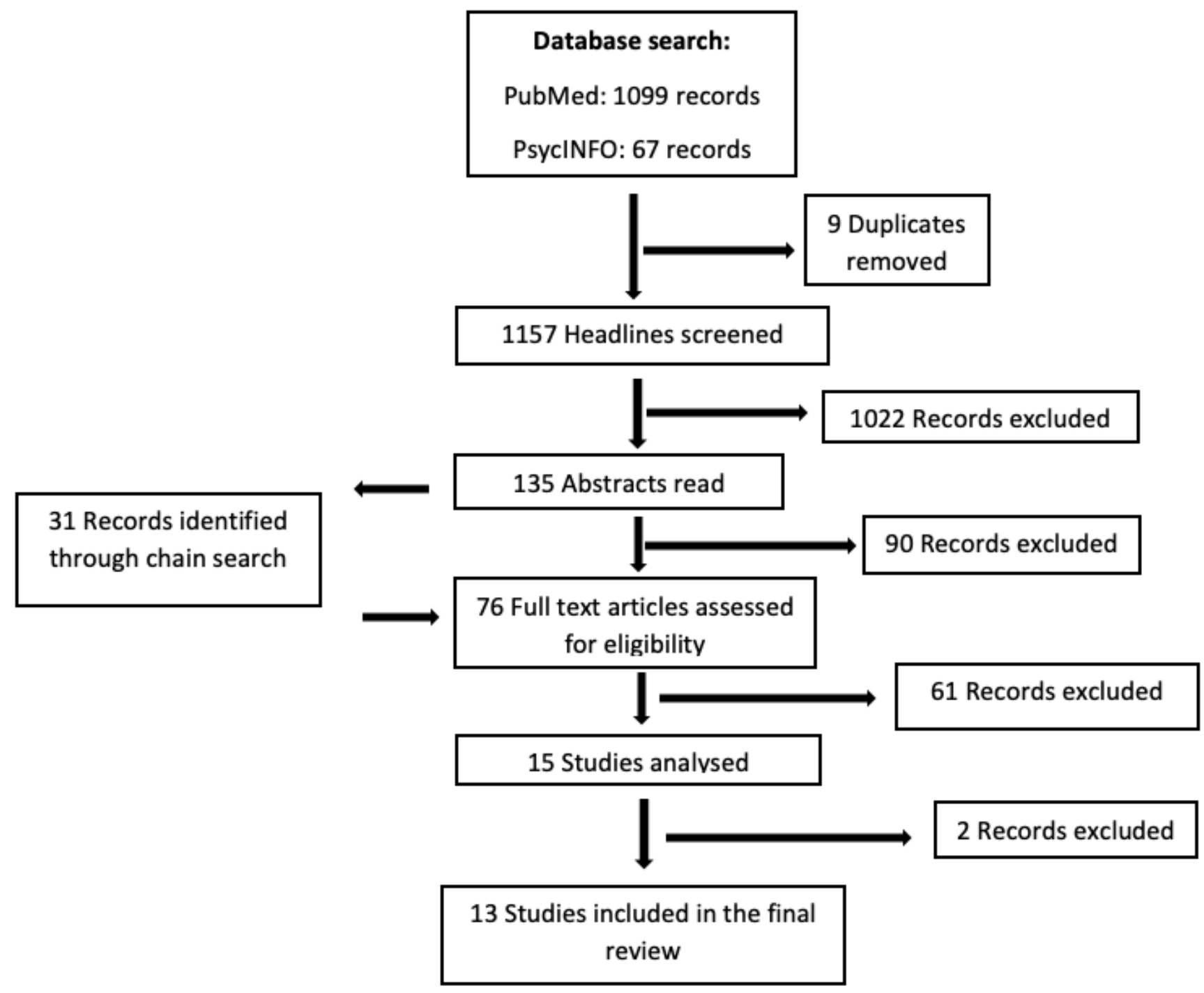

Figure 1

The database search provided 1258 hits in total, nine duplicates were removed, and 1249 articles were screened by title. 140 abstracts which matched the inclusion and exclusion criteria were reviewed. Of these, 45 papers were assessed in full-text for eligibility. The final analyses included 13 studies. 